\title{
RANCANG BANGUN MESIN PENGUPAS, PENGHANCUR DAN PENGAYAK SABUT KELAPA
}

\author{
Hari Purnomo, Dian Janari \\ Jurusan Teknik Industri, Universitas Islam Indonesia \\ haripurnomo@uii.ac.id
}

\begin{abstract}
ABSTRAK
Penggunaan serat alam sebagai bahan baku industri mempunyai beberapa kelebihan yaitu mudah didapatkan dengan harga yang murah, mudah diproses, densitasnya rendah, ramah lingkungan, dan dapat diuraikan secara biologi. Salah satu serat alam yang banyak terdapat di Indonesia yaitu serat sabut kelapa. Potensi sabut kelapa sangat besar, akan tetapi belum dapat dimanfaatkan sepenuhnya untuk kegiatan produktif karena kurangnya teknologi alat yang dapat memisahkan komponen-komponen buah kelapa. Tujuan penelitian ini adalah membuat mesin pengolah sabut kelapa tiga tahap dengan fungsi pengupas, penghancur sabut dan pengayak serat dalam satu konstruksi mesin menggunakan pendekatan ergonomi partisipatori. Hasil penelitian desain pengolah sabut kelapa dirancang dengan menggunakan penggerak mesin diesel 8 HP sebagai pengganti motor listrik, ukuran panjang pengayak $2 \mathrm{~m}$, menggunakan reducer UCF 50 untuk mengurangi kecepatan putaran menjadi 50 rpm, jaring pengayak dengan ukuran $2 \mathrm{~cm}$ agar pengayakan serat pendek menjadi lebih cepat, panjang handle dengan ukuran $11 \mathrm{~cm}$, diameter handle dengan ukuran 3,5 cm dan tinggi handle dengan ukuran $140 \mathrm{~cm}$. Rancangan mesin yang dibuat mampu mengolah 30 butir kelapa dengan waktu 43 menit atau sekitar 42 butir kelapa per jam.
\end{abstract}

Kata kunci: Sabut kelapa, mesin pengolah sabut kelapa, ergonomi partisipatori.

\section{PENDAHULUAN}

Produk dengan bahan baku serat alam telah dikembangkan sebagai upaya pemanfaatan bahan alam yang memiliki nilai rendah menjadi bernilai tinggi. Penggunaan serat alam saat ini masih dimanfaatkan untuk bahan kerajinan dengan teknologi rendah dan harga murah. Berbagai upaya telah dilakukan untuk meningkatkan nilai tambah produk dengan bahan dari serat alam. Pengembangan produk berbasis serat alam memiliki peluang sangat terbuka, karena serat alam memiliki kegunaan yang cukup luas (Syakir, 2011). Serat alam juga mempunyai beberapa kelebihan antara lain mudah didapatkan dengan harga yang murah, mudah diproses, densitasnya rendah, ramah lingkungan, dan dapat diuraikan secara biologi (Kusumastuti, 2009). Serat alam yang sering dimanfaatkan oleh para pengrajin adalah serat sabut kelapa. Ketersediaan serat sabut kelapa yang melimpah dikarenakan Indonesia mempunyai total areal perkebunan kelapa mencapai 3,29 juta ha atau sekitar 31,2 $\%$ dari total areal perkebunan kelapa dunia (Prastowo et al., 2007). Jumlah produksi sebesar 15,5 milyar butir kelapa per tahun menjadikan Indonesia sebagai negara penghasil kelapa terbesar di dunia (Darmanto, 2011). Buah kelapa terdiri dari sabut, tempurung dan daging, dimana sabut kelapa merupakan bagian terbesar dari buah kelapa, yaitu sekitar 35\% dari bobot buah kelapa (Bahtiar, 2012).

Jumlah produksi buah kelapa yang besar dapat meningkatkan limbah sabut kelapa, karena tidak dimanfaatkan dengan baik oleh para pengrajin menjadi produk bernilai guna tinggi. Sebaian besar pengrajin hanya membuat produk dengan bahan baku sabut kelapa untuk produk seperti sapu, keset dan tali. Pemanfaatan sabut kelapa yang kurang optimal dikarenakan belum intensifnya pelatihan kepada para pengrajin untuk meningkatkan nilai tambah produk yang dibuat dan kualitas sabut kelapa yang rendah. Serat sabut kelapa yang dalam perdagangan dunia dikenal dengan nama coconut coir, dapat digunakan sebagai bahan baku untuk berbagai industri, seperti industri jok untuk kendaraan, jok perabot rumah tangga, matras, kemasan, dan tali (Kustaman, 2005). Kurangnya teknologi alat yang dapat memisahkan komponen-komponen buah kelapa dan kurangnya informasi maka selama ini 
kebanyakan masyarakat khususnya petani kelapa beranggapan buah kelapa hanya dapat dimanfaatkan air dan dagingnya saja (Windriyo, 2008).

Mesin pengolahan sabut kelapa menjadi serat belakangan mulai banyak berkembang dan dapat diperoleh secara komersial, baik yang dihasilkan oleh lembaga litbang maupun oleh swasta (Subiyanto, 2000). Berbagai penelitian rancang bangun mesin sabut kelapa banyak dilakukan. Penelitian yang dilakukan oleh Ilmi (2009) yaitu rancang bangun mesin pengolah sabut pada bagian roller pengupas sabut yang mampu menghasilkan alat pengupas sabut kelapa dengan kapasitas alat sebesar 180 butir/jam. Dari hasil pengujian alat tersebut masih belum mampu mengupas sabut kelapa dengan baik (Ilmi, 2009). Penelitian tentang rancang bangun penyerat dan pemilah sabut kelapa menghasilkan alat yang dapat mengurai sabut kelapa menjadi serat dan gabus serta dapat memisahkan serat dari gabus kelapa dengan kapasitas 18.000 sabut per hari (Windriyo, 2008). Penelitian lainnya yaitu pembuatan mesin pengurai sabut kelapa menghasilkan alat pengurai sabut kelapa dengan penggerak mesin diesel sebesar $7 \mathrm{Hp}$ dengan putaran yang direduksi menjadi 850 rpm (Ferdinan, 2009).

Beberapa penelitian yang telah dihasilkan hanya berfokus pada kapasitas yang besar sehingga tidak sesuai dengan sumber daya yang dimiliki oleh petani serta dalam satu konstruksi mesin hanya memiliki satu fungsi dari beberapa tahap pengolahan sabut kelapa. Sedangkan pada penelitian ini merupakan rancang bangun mesin pengolah sabut kelapa tiga tahap dengan fungsi pengupas, penghancur sabut dan pengayak serat dalam satu konstruksi mesin. Metode yang digunakan perancangan adalah ergonomi partisipatori yang merupakan sebuah konsep dengan melibatkan pekerja secara aktif untuk terlibat dalam mengimplementasikan pengetahuan dan prosedur ergonomi di tempat kerja mereka (Nagamachi ,1995). Ergonomi partisipatori telah digunakan untuk menciptakan pekerjaan menjadi lebih terpusat pada manusia (Imada, 2000). Menurut Manuaba (2003) ergonomi partisipatori berawal dari mengorganisasi tim proyek untuk mengidentifikasi masalahmasalah ergonomi di tempat kerja dan selanjutnya melakukan pemecahan masalah secara holistik dengan melibatkan semua pihak terkait sedini mungkin melalui proses yang sistematis. Penelitian ini diawali dengan penelitian pendahuluan yaitu rancangan mesin pemecah sabut kelapa tiga tahap dengan pendekatan partisipatori (Purnomo, et al., 2013). Penelitian yang dilakukan hanya sebatas pemilihan rancangan dari tiga konsep rancangan yang diusulkan dan belum dibuat mesinnya. Penelitian selanjutnya adalah implementasi tahap pertama yang berfungsi untuk mengupas sabut kelapa (Widananto dan Purnomo, 2013). Hasil penelitian menunjukkan bahwa waktu yang dibutuhkan untuk mengupas sabut kelapa 130,33 detik per butir kelapa atau sebesar 28 butir kelapa per jam. Sedangkan pada penelitian ini merupakan penggabungan dari tiga fungsi mesin pengolah sabut kelapa yaitu pengupas, penghancur sabut dan pengayak serat.

\section{METODE PENELITIAN}

\section{A. Objek penelitian}

Objek penelitian adalah rancang bangun mesin pengolah sabut kelapa tiga tahap yang merupakan kelanjutaan penelitian terdahulu. Rancang bangun mesin pengolah sabut kelapa yang dilakukan dengan menggabungkan tiga fungsi yaitu pengupas, penghancur sabut dan pengayak serat dalam satu konstruksi mesin. Pengupas sabut kelapa berfungsi untuk memisahkan sabut kelapa dari tempurungnya dan penghancur sabut kelapa berfungsi untuk meghancurkan cocofiber dengan cocopeat sedangkan pengayak berfungsi untuk memisahkan antara cocofiber dengan cocopeat.

\section{B. Pengumpulan data}

Pengumpulan data dilakukan menggunakan metode wawancara dan studi pustaka. Wawancara, dulakukan dengan mengajukan pertanyaan secara umum kepada pemakai tentang kebutuhan terhadap mesin pengolah sabut kelapa, sedangkan studi pustaka dilakukan dengan membaca dan mempelajari beberapa referensi seperti 
literatur, laporan penelitian dan tulisan ilmiah lain yang dapat mendukung penelitian. Studi pustaka ditujukan untuk membandingkan dan memperbaiki rancangan yang dibuat.

\section{Proses perancangan}

Perancangan mesin pengolah sabut kelapa dilakukan dengan beberapa tahapan proses perancangan yaitu : (1) Proses pengembangan konsep berbasis partisipatori. Pada tahap ini dengan melibatkan pihak-pihak terkait seperti ahli ergonomi, teknik mesin, pengguna, dan pekerja bengkel. Langkah-langkah yang dilakukan dalam tahap pengembangan konsep meliputi : (a) Pemilihan anggota tim partisipatori yang terdiri dari satu orang dari teknik mesin, ahli ergonomi, pengguna dan perwakilan dari bengkel, (b) Melakukan Focus Group Discussion (FGD) dengan anggota tim partisipatori untuk mempelajari konsep desain yang telah dibuat pada penelitian terdahulu, (c) evaluasi dan memperbaiki konsep desain hasil dari FGD, (d) Melakukan perbaikan konsep hingga mendapatkan desain konsep yang disetujui oleh seluruh tim partisipatori; (2) Proses perancangan konsep. Proses perancangan pada tahap ini, dilakukan dengan mempertimbangkan aspek antropometri sesuai dengan dimensi tubuh pengguna. Ukuran dimensi tubuh yang digunakan antara lain yaitu: Lebar telapak tangan metakarpal (Ltm) digunakan untuk panjang handle menggunakan pesentil ke-95, Panjang telapak tangan (Ptt) digunakan untuk diameter handle menggunakan persentil ke-50, dan Tinggi bahu berdiri (Tbb) digunakan untuk tinggi handle menggunakan persentil ke-5; dan (3) Proses rancang bangun mesin. Rancang bangun mesin pengolah sabut kelapa dilakukan sesuai dengan desain yang telah dihasilkan dalam proses pengembangan konsep. Proses pembuatan rancang bangun mesin dilakukan dengan menggunakan bahan-bahan atau komponen-komponen yang mudah didapat dan harga yang murah tanpa mengurangi kualitasnya. Bahan yang digunakan untuk merancang mesin pengolah sabut kelapa antara lain : besi kotak L40 untuk kerangka, L30 untuk kerangka penghubung, plat ST $2 \mathrm{~mm}$ untuk penghancur dan mesin disesel dengan kemampuan $8 \mathrm{HP} / 2600 \mathrm{rpm}$.

\section{Uji coba dan analisis}

Mesin pengolah sabut kelapa tiga tahap yang dibuat selanjutnya dilakukan uji coba untuk mengolah sabut kelapa dengan 8 kali percobaan. Uji coba digunakan utuk mengetahui waktu rata-rata dan kapasitas produksi.

\section{HASIL DAN PEMBAHASAN}

\section{A. Pengembangan Konsep}

Penelitian ini merupakan perbaikan penelitian sebelumnya dan penambahan fungsi mesin. Pada penelitian sebelumnya telah dibuat rancangan mesin pencacah sabut kelapa tiga tahap berbasis partisipatori dan dilanjutkan dengan rancang bangun mesin pengupas sabut kelapa berbasis partisipatori yang merupakan bagian pertama dari desain tiga tahap yang telah dibuat. Proses perkembangan penelitian mesin pengolah sabut kelapa ditunjukkan pada Tabel 1 berikut. 
Tabel 1. Perkembangan Penelitian

\begin{tabular}{lll}
\hline \multicolumn{1}{c}{ Judul } \\
Penelitian \\
mesingan \\
pemecah \\
sabut kelapa \\
tiga tahap \\
dengan \\
pendekatan \\
partisipatori
\end{tabular}

Berikut ini adalah gambar desain awal dan tabel evaluasi perbaikan desain mesin pengolah sabut kelapa tiga tahap berbasis partisipatori. 


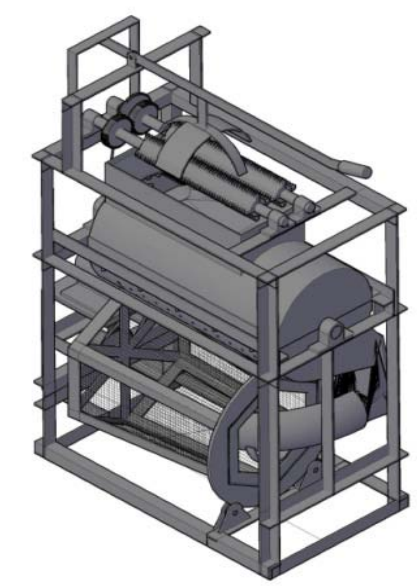

Gambar 1. Desain Awal

Rancangan awal seperti nampak pada Gambar 1, dilakukan perubahan rancangan dikarenakan : (1) Pengayak yang disatukan menjadi satu kontruksi tidak optimal dijalankan; (2) Arah keluar sabut pada mesin penghancur dipindahkan kesamping untuk memudahkan keluarnya sabut kelapa; (3) Corong masuk sabut kelapa dari mesin pengupas ke mesin penghancur dibuat lebih besar untuk kelancaran proses; (4) Penambahan reducer untuk menggerakan pengayak; dan (5) penggantian jaring pengayak. Secara rinci hasil evaluasi desain mesin lama dari tim partisipatori dan perbaikan desain ditunjukkan pada Tabel 2 berikut.

Tabel 2. Proses Evaluasi dan Perbaikan Berbasis Partisipatori

\begin{tabular}{|l|l|l|l|}
\hline No & Aspek & \multicolumn{1}{|c|}{ Evaluasi } & \multicolumn{1}{|c|}{ Perbaikan } \\
\hline 1 & Pemakai & $\begin{array}{l}\text { Penggunaan penggerak motor listrik } \\
\text { menjadikan mesin tidak dapat } \\
\text { dipindah dan kekuatannya kurang. }\end{array}$ & $\begin{array}{l}\text { Penggerak motor listrik } \\
\text { diganti menjadi mesin } \\
\text { diesel. }\end{array}$ \\
\hline 2 & $\begin{array}{l}\text { Ahli } \\
\text { mesin }\end{array}$ & $\begin{array}{l}\text { Kekuatan motor listrik kurang } \\
\text { mampu untuk dijadikan penggerak } \\
\text { mesin pengolah sabut kelapa tiga } \\
\text { tahap }\end{array}$ & $\begin{array}{l}\text { Penggantian penggerak dari } \\
\text { motor listrik menjadi mesin } \\
\text { diesel 8 HP. }\end{array}$ \\
\hline 3 & $\begin{array}{l}\text { Ahli } \\
\text { mesin }\end{array}$ & $\begin{array}{l}\text { Panjang pengayak dengan ukuran } \\
70 \text { cm tidak mampu menghasilkan } \\
\text { serat yang bersih dari gabus. }\end{array}$ & $\begin{array}{l}\text { Memperpanjang ukuran } \\
\text { pengayak menjadi 2 meter. }\end{array}$ \\
\hline 4 & $\begin{array}{l}\text { Ahli } \\
\text { ergonomi }\end{array}$ & $\begin{array}{l}\text { Kecepatan putaran pada bagian } \\
\text { pengayak terlalu kencang sehingga } \\
\text { berbahaya }\end{array}$ & $\begin{array}{l}\text { Mengurangi kecepatan } \\
\text { putaran pengayak }\end{array}$ \\
\hline 5 & $\begin{array}{l}\text { Teknisi } \\
\text { bengkel }\end{array}$ & $\begin{array}{l}\text { Kecepatan putaran pada bagian } \\
\text { pengayak terlalu kencang membuat } \\
\text { gabus susah keluar dari pengayak. }\end{array}$ & $\begin{array}{l}\text { Dipasang reducer UCF 50 } \\
\text { agar kecepatan putaran } \\
\text { menjadi 50 rpm }\end{array}$ \\
\hline 6 & $\begin{array}{l}\text { Teknisi } \\
\text { bengkel }\end{array}$ & $\begin{array}{l}\text { Pengayak yang diletakkan di bawah } \\
\text { pencacah akan membuat aliran sabut } \\
\text { kurang lancar. }\end{array}$ & $\begin{array}{l}\text { Meletakkan pengayak } \\
\text { memanjang ke samping } \\
\text { tidak searah dengan } \\
\text { pencacah dan tanpa } \\
\text { menggunakan elbow. }\end{array}$ \\
\hline 7 & $\begin{array}{l}\text { Teknisi } \\
\text { bengkel }\end{array}$ & $\begin{array}{l}\text { Jaring pengayak 1 cm membuat } \\
\text { proses pengayakan serat pendek } \\
\text { berlangsung lama. }\end{array}$ & $\begin{array}{l}\text { Mengganti jaring pengayak } \\
\text { dengan ukuran 2 cm agar } \\
\text { pengayakan serat pendek } \\
\text { menjadi lebih cepat. }\end{array}$ \\
\hline
\end{tabular}




\begin{tabular}{|c|c|c|c|}
\hline 8 & $\begin{array}{l}\text { Ahli } \\
\text { ergonomi }\end{array}$ & $\begin{array}{l}\text { Mesin yang tinggi akan menyulitkan } \\
\text { operator dalam mengoperasikannya. }\end{array}$ & $\begin{array}{l}\text { Membuat alas pada bagian } \\
\text { samping mesin dengan } \\
\text { ketinggian yang sesuai. }\end{array}$ \\
\hline 9 & $\begin{array}{l}\text { Ahli } \\
\text { ergonomi }\end{array}$ & $\begin{array}{l}\text { Pada bagian pengupas yang akan } \\
\text { ditambah puly untuk mengurangi } \\
\text { kecepatan putaran menyebabkan } \\
\text { posisi operator kurang aman karena } \\
\text { berada di belakang puly. }\end{array}$ & $\begin{array}{l}\text { Merubah posisi pencekam } \\
\text { kelapa menjadi } \\
\text { menyamping. }\end{array}$ \\
\hline 10 & $\begin{array}{l}\text { Ahli } \\
\text { Ergonomi }\end{array}$ & $\begin{array}{l}\text { Untuk kenyaman penggunaan perlu } \\
\text { dirancang panjang handle, diameter } \\
\text { handle dan tinggi handle. . }\end{array}$ & $\begin{array}{l}\text { a. Panjang handle dengan } \\
\text { ukuran } 11 \mathrm{~cm} \text {, } \\
\text { menggunakan dimensi } \\
\text { Ltm } \\
\text { b. Diameter handle dengan } \\
\text { ukuran } 3,5 \mathrm{~cm} \text {, } \\
\text { menggunakan dimensi Ptt } \\
\text { c. Tinggi handle dengan } \\
\text { ukuran } 140 \mathrm{~cm} \text {, } \\
\text { menggunakan dimensi } \\
\text { Tbb }\end{array}$ \\
\hline
\end{tabular}

Hasil perbaikan rancangan mesin pengolah sabut kelapa dari tim partisipatori ditunjukan pada Gambar 2 berikut.
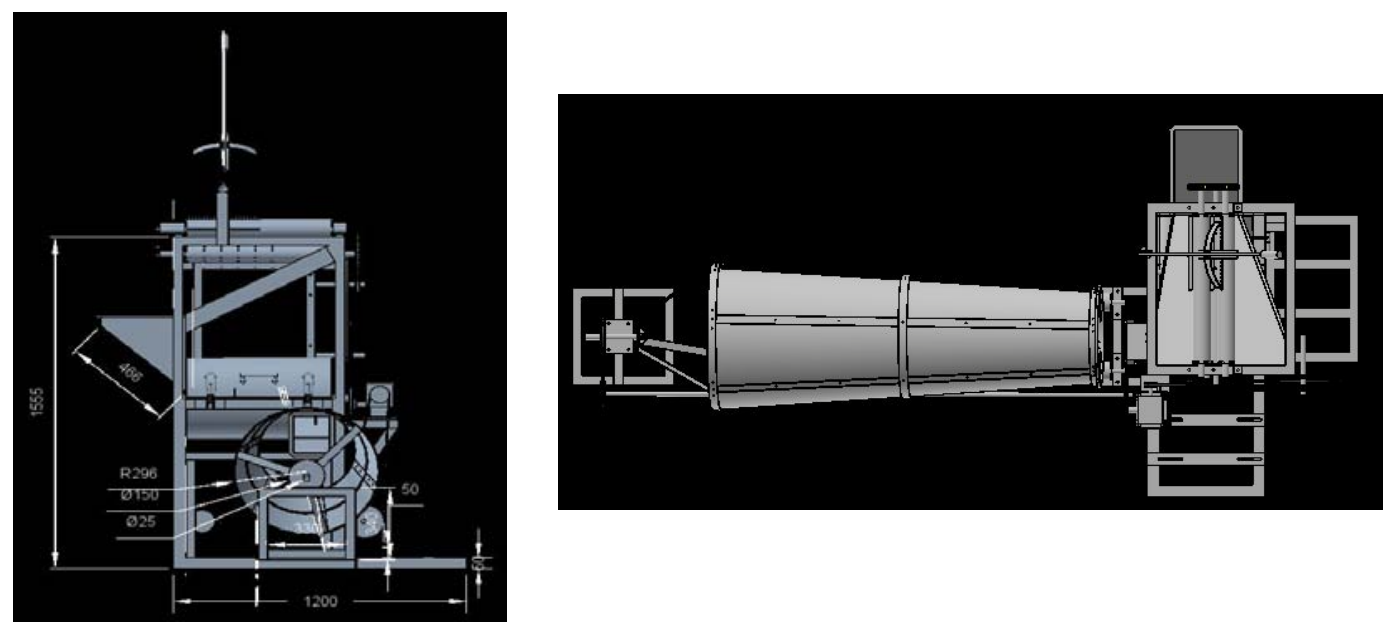

Pandangan depan (a) Pandangan atas (b)

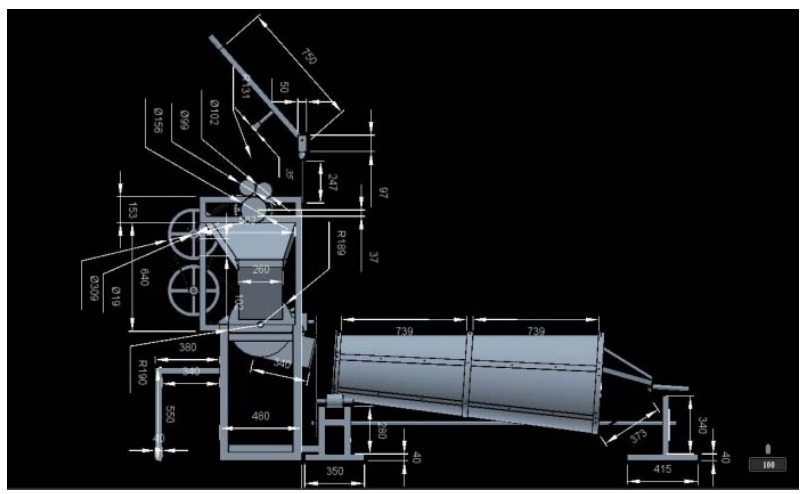

Pandangan samping (c) 
Gambar 2. Rancangan akhir mesin pengupas, penghancur dan pengayak sabut kelapa : pandangan depan (a), pandangan atas (b) dan pandangan samping (c)

Berdasarkan hasil eksperiman untuk rancangan perbaikan mesin pengupas, penghancur dan pengayak sabut kelapa mampu mengolah dengan rerata 30 butir kelapa dalam waktu 43 menit atau sekitar 42 butir kelapa per jam. Penelitian ini masih memiliki beberapa keterbatasan, antara lain : (1) Bagian pengayak yang panjang dan posisinya yang tidak searah dengan dua bagian mesin yang lain membuat mesin ini terlihat kurang rapi dan berukuran lebih besar; (2) Penggunaan puly untuk mereduksi kecepatan putaran membuat mesin terlihat kurang rapi dan berbahaya; dan (3) Gear penyalur daya terbuat dari bahan berkualitas rendah sehingga tingkat keawetannya kurang.

\section{KESIMPULAN DAN SARAN}

\section{A. KESIMPULAN}

Berdasarkan hasil penelitian dapat disimpukan bahwa rancangan mesin pengupas, penghancur dan pengayak sabut kelapa dirancang menggunakan penggerak mesin diesel $8 \mathrm{HP}$ sebagai pengganti motor listrik, ukuran panjang pengayak $2 \mathrm{~m}$, menggunakan reducer UCF 50 untuk mengurangi kecepatan putaran menjadi 50 rpm, menggunakan jaring pengayak dengan ukuran $2 \mathrm{~cm}$ agar pengayakan serat pendek menjadi lebih cepat, panjang handle dengan ukuran $11 \mathrm{~cm}$, diameter handle dengan ukuran 3,5 cm dan tinggi handle dengan ukuran $140 \mathrm{~cm}$. Rancangan mesin yang dibuat mampu mengolah dengan rerata 30 butir kelapa dalam waktu 43 menit. Dengan demikian dapat diketahui kapasitas produksi mesin pengolah sabut kelapa sekitar 42 butir kelapa per jam.

\section{B. SARAN}

Hasil penelitian ini disadari masih banyak kekurangan terutama pada dimensi pengayak dan peralatan yang digunakan. Saran peneliti terkait dengan keberlanjutan rancang bangun mesin pengolah sabut kelapa tiga tahap berbasis ergonomi partisipatori adalah :

a. Perlu dilakukan perbaikan terkait dengan ukuran pengayak yang terlalu panjang

b. Perlu dianalisis kembali proses pengupasan dengan mempertimbangkan kecepatan putar dan kualitas material.

c. Perlu ditinjau kembali ukuran alat secara keseluruhan disesuaikan dengan dimensi tubuh pekerja dengan memperkecil ukuran mesin.

\section{DAFTAR PUSTAKA}

[1] Bahtiar, A. D. M. (2012). Aplikasi Serat Serabut Kelapa Bermatrik Sagu dan Gliserol Sebagai Pengganti Kemasan Makanan Dari Stereofoam. Dibaca tanggal 30 Januari 2013. Tersedia di http://www.poltek-kediri.ac.id/

[2] Darmanto. (2011). Peningkatan Kekuatan Serat Serabut Kelapa Dengan Perlakuan Silane. Dibaca tanggal 30 Januari 2013. Tersedia di http://eprints.undip.ac.id/

[3] Ferdinan. (2009). Perencanaan dan Pembuatan Mesin Pengurai Serabut Kelapa. Dibaca tanggal 15 juni 2012. Tersedia di. http://digilib.petra.ac.id/

[4] Ilmi, A. R. (2009). Rancang Bangun Pengupas Sabut pada Alat Pengolah Sabut Kelapa. Skripsi. Institut Teknologi Sepuluh Nopember.

[5] Imada, A. (2000). Participatory Ergonomics: a strategy for creating human-centred work. Journal of Science of Labour, 76 (3 Pt.2), 25-31.

[6] Kustaman, P. H. (2005). Analisis Respon Penawaran Ekspor Serat Sabut Kelapa Indonesia. Skripsi. Program Studi Ekstensi Manajemen Agribisnis Fakultas Pertanian Institut Pertanian Bogor. 
[7] Kusumastuti, A. (2009). Aplikasi Serat Sisal sebagai Komposit Polimer. Dibaca tanggal 30 Januari 2013. Tersedia di http://journal.unnes.ac.id/

[8] Manuaba, A. (2003). Aplikasi Ergonomi Dengan Pendekatan Holistik Perlu, Demi Hasil Yang Lebih Lestari dan Mampu Bersaing. Makalah. Temu Ilmiah dan Musyawarah Nasional Keselamatan dan Kesehatan Kerja Ergonomi. Hotel Sahid Jakarta.

[9] Nagamachi, M. (1995). Requisites and Practice of Participatory Ergonomic. International Journal of Industrial Ergonomics, Vol. 15, No. 5. pp. 371-377.

[10] Prastowo, B., Mahmud, Z., Wahyudi, A., Hardono, G. S., Novarianto, H., Luntungan, H. T. dan Efendi, D. S. (2007). Prospek dan Arah Pengembangan Agribisnis Kelapa. Edisi Kedua. Dibaca tanggal 27 Januari 2013. Tersedia di http://www.litbang.deptan. go.id/

[11] Purnomo, H., Janari, D. dan Widananto, H. (2013). Rancangan Mesin Pemecah Sabut Kelapa Tiga Tahap Dengan Pendekatan Partisipatori. Prosiding Seminar Nasional 8 Teknik Mesin. Universitas Kristen Petra Surabaya.

[12] Subiyanto. (2000). Prospek Industri Pengolahan Limbah Sabut Kelapa. Dibaca tanggal 30 Januari 2013. Tersedia di http://ejurnal.bppt.go.id/

[13] Syakir, M. 2011. Inovasi Teknologi Mendukung Pengembangan Serat Alam Nasional. Dibaca tanggal 30 Januari 2013. Tersedia di http://perkebunan.litbang.deptan.go.id/

[14] Widananto, H dan Purnomo, H. (2013). Rancangan Mesin Pengupas Sabut Kelapa Berbasis Ergonomi Partisipatori. Prosiding IENACO, Inovasi Teknologi untuk Kemandirian Bangsa. UMS Surakarta

[15] Windriyo, B. T. (2008). Tugas Akhir "Rancang Bangun Penyerat dan Pemilah pada Alat Pengolah Sabut Kelapa”. Surabaya: Jurusan Teknik Mesin Fakultas Teknologi Industri Institut Teknologi Sepuluh Nopember. 